\title{
I mpact of economic crisis on indications for general versus local anaesthesia in head and neck surgery: a single centre analysis
}

\author{
Tatjana Goranovic, Boris Simunjak, Dinko Tonkovic, Miran Martinac \\ Sveti Duh University Hospital, Croatia
}

Correspondence: Tatjana Goranovic. Address: Sveti Duh University Hospital, Department of Anaesthesiology and Intensive Care Medicine, Sveti Duh 64, 10000 Zagreb, Croatia. E-mail: tanjagoranovic@hotmail.com

Received: June 10, 2014

Accepted: September 25, 2014

Online Published: October 13, 2014

DOI : $10.5430 /$ jha.v3n6p92

URL: http://dx.doi.org/10.5430/jha.v3n6p92

\section{Abstract}

Objective: To analyze the impact of the hospital board's cost saving measure on physicians' decision to indicate head and neck surgery according to the type of anaesthesia (general versus local).

Methods: Design: a retrospective analysis of medical charts on head and neck surgery and anaesthesia covering 2011-2012. Setting: department of otorhinolaryngology and head and neck surgery, university hospital, Croatia. Participants: patients undergoing head and neck surgery. Intervention(s): reduction of departmental financial fund for general anaesthesia for $10 \%$. Main Outcome Measure(s): an overall of number of head and neck surgeries performed in general versus local anaesthesia before and after the implementation of the intervention measure.

Results: There were a total of 984 head and neck surgeries in general anaesthesia in 2011 and 861 in 2012 . There were a total of 460 head and neck surgeries in local anaesthesia in 2011 and 528 in 2012. The performance of head and neck surgeries in general anaesthesia was significantly reduced in a year after the implementation of the intervention $(p=.01)$ There was no statistical significant difference in the performance of head and neck surgeries in local anaesthesia before and after the intervention.

Conclusions: The reduction of departmental fund for general anaesthesia as a cost saving method resulted only in reducing the total performance of surgeries in general anaesthesia without any switch to performing surgeries in local anaesthesia. It seems that the hospital board's cost saving measure did not have any impact on physicians' decisions to indicate more surgeries in local anaesthesia.

\section{Key words}

Economic crisis, Head and neck surgery, Anaesthesia, Local

\section{I ntroduction}

By now the global economic crisis, started in Iceland in 2008, has hit most of European countries with its implications on healthcare system as well. To cope with the crisis challenge different healthcare managerial strategies have been implemented in different European countries including strong reduction of costs ${ }^{[1]}$, reallocation of the healthcare costs from the public purse to private households ${ }^{[1]}$, and changes in pharmaceutical policies (e.g. price cuts, changes in co- 
payments and VAT rates on medicines ${ }^{[2]}$, changes in the profit margins of pharmacies and wholesalers, and tenders for hospital drugs ${ }^{[3]}$ ). On local level at public hospitals, hospitals' directors and managers follow their governors' recommendations and implement changes and different bundles of measures.

General anaesthesia compared to local anaesthesia implies more costs ${ }^{[4-6]}$. Different anesthesia subspecialties show significant and financially important differences regarding their specific costs ${ }^{[7]}$. Most major head and neck surgeries are performed under general anaesthesia (e.g. laryngectomy, neck dissection, septorhinoplasty, uvulopalotopharyngoplasty, partial or total thyreoidectomy, paediatric adenotonsillectomy). Only minor (e.g. skin excisions) are routinely performed under local anaesthesia. However, some surgery (e.g. septoplasty, adult tonsillectomy) can be performed under local anaesthesia if well planned, but for the comfort of the patient and the surgeon are mostly done under general anaesthesia.

At the beginning of 2012, as a general cost saving measure our hospital board decided to reduce departmental fund for general anaesthesia for $10 \%$. One year later following this hospital managers' decision, we performed an analysis of head and neck surgeries performed according to the type and cost of anaesthesia (costly general versus cheaper local). The aim of this study was to analyze the impact of the implementation of the cost saving measure of reducing departmental fund for general anaesthesia on physicians' decision to indicate head and neck surgery according to the type of anaesthesia (general versus local) in which it can be safely performed and accordingly plan the daily elective surgery list.

\section{Methods and patients}

We retrospectively reviewed the performance of all elective surgery and anaesthesia at Department of Otorhinolaryngology and Head and Neck Surgery (surgical DRG groups 011-013, 129-139 and 625-627), at Sveti Duh University Hospital, Zagreb, Croatia in the period from the beginning of January 2011 till the end of December 2012. In a designed questionnaire we collected data on the type of surgery and the type of anaesthesia (general, local). General anaesthesia included any application of opioids or anaesthetics during surgery no matter which method of securing the airway was used (oral mask, laryngeal mask, oroenotracheal tube, nasoendotracheal tube, tracheal canula). During general anaesthesia an anaesthesiologist was always present to perform the standard monitoring during surgery. Local anaesthesia implied the application of local anaesthetics in a surgical field by a surgeon himself without the presence of the anaesthesiologists.

Statistical analysis was performed with SPSS software for Windows, version 9.0 (SPSS Inc., Chicago, IL, USA). Numerical data were presented in absolute and percentage. Distribution of numerical data was determined with the Kolmogorov-Smirnov test and the Shapiro Wilk test of normality. Normally distributed data were expressed as mean \pm standard deviation $(S D)$, whereas not normally distributed data were presented as median with interquartile range (IQR). Mann Whitney test was used for comparison of intergroup differences. $P<.05$ was considered statistically significant.

\section{Results}

There were a total of 984 performed head and neck surgeries in general anaesthesia in 2011 and 861 in 2012. There were a total of 460 performed head and neck surgeries in local anaesthesia in 2011 and 528 in 2012. Table 1 and 2 shows the month distribution of performed surgeries under general and local anaesthesia in the year before the intervention (2011) and after the intervention (2012).

There was the statistical significant reduction of performance of head and neck surgeries in general anaesthesia in 2012, in a year after the implementation of the intervention $(p=.01)$. There was no statistical significant difference in the performance of head and neck surgeries in local anaesthesia in 2011 and 2012 (see the figure). 
Table 1. Monthly distribution of the performance of head and neck surgeries in local anaesthesia (LA) and general anaesthesia (GA) before (2011) and after (2012) the intervention (number [n] and percentage [\%] in parenthesis)

\begin{tabular}{|c|c|c|c|c|}
\hline \multirow{2}{*}{ Month } & \multicolumn{2}{|c|}{2011} & \multicolumn{2}{|c|}{2012} \\
\hline & LA n (\%) & GA n (\%) & LA n (\%) & GA (\%) \\
\hline Jan & $24(5.22)$ & $94(9.55)$ & $53(10.04)$ & $71(8.25)$ \\
\hline Feb & $27(5.87)$ & $86(8.47)$ & $47(8.90)$ & $80(9.29)$ \\
\hline Mar & $51(11.09)$ & $95(9.65)$ & $53(10.04)$ & $79(9.18)$ \\
\hline Apr & $36(7.83)$ & $81(8.23)$ & $36(6.82)$ & $67(7.78)$ \\
\hline May & $36(7.83)$ & $85(8.64)$ & $51(9.66)$ & $64(7.43)$ \\
\hline Jun & $51(11.09)$ & $74(7.52)$ & $51(9.66)$ & $60(6.97)$ \\
\hline Jul & $46(10.00)$ & $90(9.15)$ & $31(5.87)$ & $81(9.41)$ \\
\hline Aug & $25(5.43)$ & $71(7.22)$ & $24(4.55)$ & $58(6.74)$ \\
\hline Sep & $38(8.26)$ & $69(7.01)$ & $44(8.33)$ & $67(7.78)$ \\
\hline Oct & $40(8.69)$ & $72(7.32)$ & $45(8.52)$ & $76(8.83)$ \\
\hline Nov & $54(11.74)$ & $84(8.54)$ & $51(9.66)$ & $91(10.55)$ \\
\hline Dec & $32(6.95)$ & $83(8.43)$ & $42(7.95)$ & $67(7.78)$ \\
\hline Total & $460(100)$ & 984 (100) & $528(100)$ & $861(100)$ \\
\hline
\end{tabular}

Table 2. Comparing changes in LA and GA 2011-2012

\begin{tabular}{lllll}
\hline \multirow{2}{*}{ Obs. } & \multicolumn{2}{c}{ Year (\% of change) } & & \multicolumn{1}{c}{ Test } \\
\cline { 2 - 3 } & $\mathbf{2 0 1 1}$ (Obs.) & $\mathbf{2 0 1 2 ( O b s . )}$ & & Mann-Whitney Test $\boldsymbol{P}$-value \\
\hline LA & 460 & $528(14.8)$ & .219 \\
GA & 984 & $861(-12.5)$ & .010 \\
\hline
\end{tabular}

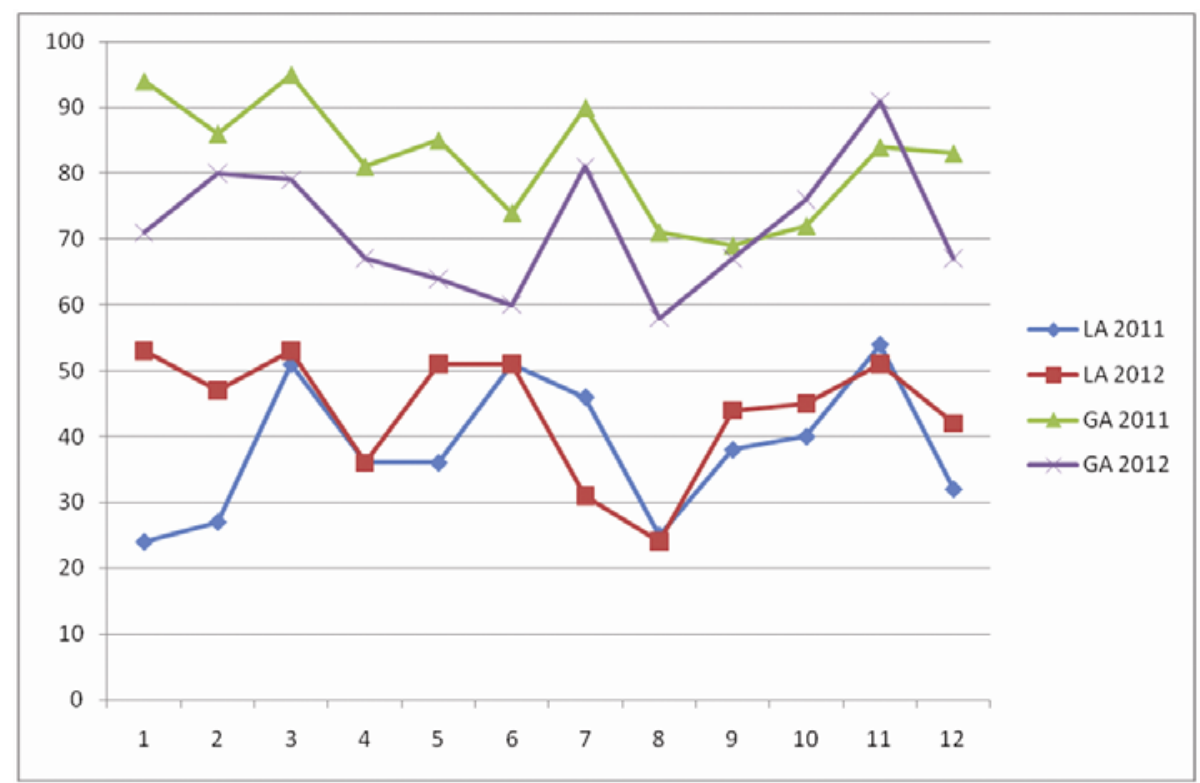

Figure. Comparison of performance of head and neck surgeries in local anaesthesia (LA) and general anaesthesia (GA) before (2011) and after (2012) the intervention (GA in 2012 vs. 2011 was significantly reduced [ $p=.01]$ ).

\section{Discussion}

In this study we reviewed the impact of the hospital board's cost saving measure of the departmental fund reduction for general anaesthesia on physicians' decision to indicate head and neck surgery according to the type of anaesthesia (general 
versus local). The reduction of total general anaesthesia that followed hospital board's cost saving measure was expected because it was simple implementation of their decision. However, unexpectedly we did not prove our hypothesis since we did not show any significant increase in head and neck surgeries in local anaesthesia.

We chose the department of otorhynolaryngology and head and neck surgery because the diversity of surgical procedures allows the use of both types of anaesthesia ${ }^{[8]}$. Paediatric patients are traditionally performed under general anaesthesia ${ }^{[9]}$, but increasing number of certain head and neck surgeries in adults can be performed in general and local anaesthesia with equal ease and safety. Moreover, cosmetic plastic head and neck surgeries showed a clear trend toward the increasing use of local anaesthetics ${ }^{[10]}$. Septoplasties are well documented example of suitable operations for short-stay surgery under local anaesthesia ${ }^{[11,12]}$. In addition there are emerging new methods such as voice prosthesis insertion ${ }^{[13]}$ and tracheooesophageal puncture ${ }^{[14]}$ that require no general anaesthesia but can also be performed in local anaesthesia. Parotidectomy under local anaesthesia can be conducted successfully and avoid the adverse effect of general anaesthesia ${ }^{[15]}$. If the parathyroid adenoma is localizated, minimally invasive parathyreoidectomy under only local anesthesia can be performed with a high success rate ${ }^{[16]}$. Sialendoscopy performed with local anaesthesia is well tolerated, provided that the patient has a good general health status and the operative procedure is not expected to be complex or longlasting ${ }^{[17]}$. The realization of the cochlear implant surgery under local anaesthesia and sedation is perfectly feasible with some advantages over general anaesthesia ${ }^{[18]}$.

From financial point of view, local anaesthesia in head and neck surgery, when feasible, is cheaper. Naidu et el showed that in-office cup biopsies of laryngopharyngeal tumour are safe and considerably more cost-effective compared to the performance in operating room under general anaesthesia ${ }^{[19]}$. Similarly, Bové et al. demonstrated that office-based injection laryngoplasty is both clinically and financially effective, providing patients with a convenient and flexible alternative to operating room-based intervention for glottal insufficiency ${ }^{[20]}$. Our study showed a little but statistically insignificant increase in absolute number of head and neck surgeries performed in local anaesthesia. We can speculate that our physicians were neither enough motivated nor technically skilled to switch the current clinical practice. Each new technique requires time and experience to reach a level of excellence ${ }^{[21]}$. Indeed, in a studied period there was neither any new additionally educational activity at the Department nor change in the award system for the result performance. In our study the head and neck surgeons passively obeyed hospital board's decisions without implementing any new clinical practice.

In conclusion, the reduction of departmental fund for general anaesthesia as a sole cost saving method resulted only in reducing the total performance of head and neck surgeries in general anaesthesia without any switch to performing surgeries in local anaesthesia. It seems that the hospital board's cost saving measure did not have any impact on physicians' decisions to indicate more, even when possible, head and neck surgeries in local anaesthesia instead of general anaesthesia in order to keep the total departmental surgical performance unchanged.

\section{Acknowledgements}

We thank Dr. Branko Kolarić for performing statistical analysis.

\section{Competing interests}

The authors declare that they have no competing interests.

\section{References}

[1] Nuti S, Vainieri M, Frey M. Healthcare resources and expenditure in financial crisis: scenarios and managerial strategies. J Matern Fetal Neonatal Med. 2012; 25 Suppl 4: 48-51. PMid: 22958014. http://dx.doi.org/10.3109/14767058.2012.715022

[2] Vogler S, Zimmermann N, Leopold C, De Joncheere K. Pharmaceutical policies in European countries in response to the global financial crisis. South Med Rev. 2011; 4: 69-79. PMid: 23093885. http://dx.doi.org/10.5655/smr.v4i2.1004 
[3] Vandoros S, Stargardt T. Reforms in the Greek pharmaceutical market during the financial crisis. Health Policy. 2013; 109 : 1-6. PMid: 22959163. http://dx.doi.org/10.1016/j.healthpol.2012.08.016

[4] Gomes M, Soares MO, Dumville JC, Lewis SC, Torgerson DJ, Bodenham AR, et al. GALA Collaborative Group. Cost-effectiveness analysis of general anaesthesia versus local anaesthesia for carotid surgery (GALA Trial). Br J Surg. 2010; 97: 1218-25. PMid: 20602498. http://dx.doi.org/10.1002/bjs.7110

[5] Ahonkallio S, Santala M, Valtonen H, Martikainen H. Cost-minimisation analysis of endometrial thermal ablation in a day case or outpatient setting under different anaesthesia regimens. Eur J Obstet Gynecol Reprod Biol. 2012; 162: 102-4. PMid: 22386679. http://dx.doi.org/10.1016/j.ejogrb.2012.01.025

[6] Covarelli P, Badolato M, Tomassini GM, Poponesi V, Listorti C, Castellani E, et al. Sentinel lymph node biopsy under local anaesthesia versus general anaesthesia:reliability and cost-effectiveness analysis in 153 patients with malignant melanoma. In Vivo. 2012; 26: 315-8. PMid: 22351676.

[7] Schuster M, Standl T, Wagner JA, Berger J, Reimann H, Am Esch JS. Effect of different cost drivers on cost per anesthesia minute in different anesthesia subspecialties. Anesthesiology. 2004; 101: 1435-43. PMid: 15564953. http://dx.doi.org/10.1097/00000542-200412000-00026

[8] Herlich A. Focused local anesthesia and analgesia for head and neck surgery. Int Anesthesiol Clin. 2012; 50: 13-25. PMid: 22227420. http://dx.doi.org/10.1097/AIA.0b013e318218f6ee

[9] Voronov P, Suresh S. Head and neck blocks in children. Curr Opin Anaesthesiol. 2008; 21: 317-22. PMid: 18458548. http://dx.doi.org/10.1097/ACO.0b013e3282fbf557

[10] Koeppe T, Constantinescu MA, Schneider J, Gubisch W. Current trends in local anesthesia in cosmetic plastic surgery of the head and neck: results of a German national survey and observations on the use of ropivacaine. Plast Reconstr Surg. 2005; 115: 1723-30. PMid: 15861081. http://dx.doi.org/10.1097/01.PRS.0000161671.34502.40

[11] Srinivasan V, Arasaratnam RB, Jankelowitz GA. Day-case septal surgery under general anaesthesia and local anaesthesia with sedation. J Laryngol Otol. 1995; 109: 614-7. PMid: 7561467. http://dx.doi.org/10.1017/S0022215100130853

[12] Hytönen M, Blomgren K, Lilja M, Mäkitie AA. How we do it: septoplasties under local anaesthetic are suitable for short stay surgery; the clinical outcomes. Clin Otolaryngol. 2006; 31: 64-8. PMid: 16441807. http://dx.doi.org/10.1111/j.1749-4486.2006.01139.x

[13] Fukuhara T, Fujiwara K, Nomura K, Miyake N, Kitano H. New method for in-office secondary voice prosthesis insertion under local anesthesia by reverse puncture from esophageal lumen. Ann Otol Rhinol Laryngol. 2013; 122: 163-8. PMid: 23577568.

[14] Trivedi NP, Kekatpure V, Kuriakose MA, Iyer S. Safe and simple method for secondary tracheoesophageal puncture using curved forceps. J Laryngol Otol. 2009; 123(10): e19. PMid: 18501036. http://dx.doi.org/10.1017/S0022215108002715

[15] Karahan Ö, Okus A, Sevinç B, Eryilmaz MA, Ay S, Çayci M, et al. Minimally invasive parathyroidectomy under local anesthesia. J Postgrad Med. 2013; 59: 21-4. PMid: 23525054. http://dx.doi.org/10.4103/0022-3859.109485

[16] Chow TL, Choi CY, Lam SH. Parotidectomy under local anesthesia--report of 7 cases. Am J Otolaryngol. 2013; 34: 79-81. PMid: 23218115. http://dx.doi.org/10.1016/j.amjoto.2012.08.012

[17] Luers JC, Stenner M, Schinke M, Helmstaedter V, Beutner D. Tolerability of sialendoscopy under local anesthesia. Ann Otol Rhinol Laryngol. 2012; 121: 269-74. PMid: 22606931.

[18] Hamerschmidt R, Moreira AT, Wiemes GR, Tenório SB, Tâmbara EM. Cochlear implant surgery with local anesthesia and sedation: comparison with general anesthesia. Otol Neurotol. 2013; 34: 75-8. PMid: 23187931. http://dx.doi.org/10.1097/MAO.0b013e318278c1b2

[19] Naidu H, Noordzij JP, Samim A, Jalisi S, Grillone GA. Comparison of efficacy, safety, and cost-effectiveness of in-office cup forcep biopsies versus operating room biopsies for laryngopharyngeal tumors. J Voice. 2012; 26: 604-6. PMid: 22521530. http://dx.doi.org/10.1016/j.jvoice.2011.10.003

[20] Bové MJ, Jabbour N, Krishna P, Flaherty K, Saul M, Wunar R, et al. Operating room versus office-based injection laryngoplasty: a comparative analysis of reimbursement. Laryngoscope. 2007; 117: 226-30. PMid: 17204989. http://dx.doi.org/10.1097/01.mlg.0000250898.82268.39

[21] Neudert M, Kluge A, Beleites T, Kemper M, Zahnert T. Microsurgical skills training with a new tympanoplasty model: learning curve and motivational impact. Otol Neurotol. 2012; 33: 364-70. PMid: 22089999. http://dx.doi.org/10.1097/MAO.0b013e318238081c 